\title{
SURFACE WATER DYNAMICS OF INLAND WATER BODIES OF INDIA USING GOOGLE EARTH ENGINE
}

\author{
Ashwin Gujrati ${ }^{1 * *}$ and Vibhuti Bhushan Jha ${ }^{1}$ \\ Space Applications Centre, Ahmedabad, India. - (ashwin8199,vbjha)@ sac.isro.gov.in
}

Commission V, WG V/8

KEYWORDS: Open API, Google Earth Engine, Surface extent, NDVI, MNDWI.

\begin{abstract}
:
Dynamics, distribution and quality of water has a direct impact on environment and its dependent human activities. Regular monitoring of these hydrological processes help in understanding water cycle and better management policy making. Recent increase in remote sensing satellites offer multiple observations with high spatial and temporal resolution, thus calling for extensive use of high end computational resources. Google Earth Engine(GEE) is an open Application Programing Interface (API), which offers free computational resources and satellite data on cloud computational platform minimising the users need for computational resources and data availability. Five year Landsat-8 imagery (2013-18) from GEE database has been used to study the surface water extent of large inland water bodies (surface area greater than 6000ha) of India. We have used a pixel based classification system to delineate water and non-water pixels. A knowledge based Decision Tree (DT) model has been employed to cluster the classes according to Normalized Difference Vegetation Index (NDVI) and Modified Normalized Difference Water Index (MNDWI) distribution. We report an anomalous departure from the 5-year trend line suggesting that the maximum decrease of water extent was found in year 2015-2016. Analysis of the decay pattern of reservoirs can provide timely inputs for better policy making and management of water resources. To understand the decay pattern, a Modified Gaussian model fit on time series of surface extent helps to determine maximum water extent, peak extent day and storage cycle of the water body.
\end{abstract}

\section{INTRODUCTION}

Terrestrial water is a valuable natural resource for sustaining life and also plays a major role in the global water cycle. Terrestrial waters include rivers, lakes, manmade reservoirs and wetlands. These water bodies undergo episodically change in inundated areas, therefore its mapping is crucially important. Inland waters interact directly with the ocean and atmosphere through vertical and horizontal mass fluxes (Papa et al. 2008). Hence, surface water extent and its storage is important to understand the water dynamics and the global water cycle. Wetlands perform some crucial functions in the form of groundwater recharge (Winter 2001; Ferone and Devito 2004), mitigation of floods (Junk 2005), nutrient retention (Seitzinger 1994) etc. Despite the multifarious benefits of wetland ecosystems, they are at a constant threat due to rising sea level, altered nutrient and sediment transport. Changes in distribution and quality of water over large geospatial scale is best analysed by remote sensing observations. Satellite observations pave way for large spatial and temporal analysis of the surface water dynamics. Coupled with the hydrological model of the wetlands (Hammer et al 1986, Liang et al 1994), these observations can provide useful information in the form of spatial extent, drying pattern and bathymetry.

India is bestowed with different wetland classes, an extensive study on which, has been previously carried out in National Wetland Inventory and Assessment during the 2007-2011 period (Panigrahy et al, 2012). The study estimated the total surface extent of wetlands to be around
15.26 million hectares which amounts to $4.63 \%$ of geographical area of India. Wetland monitoring through remote sensing has it's own challenges owing to the altered spectral characteristics of constituents in different seasons. Furthermore, fuzziness in delineation of the wetland boundary arises due to narrow ecotones which call for special algorithms (Gallant 2015). Despite these challenges, remote sensing with it's spatial and temporal scale is a viable candidate for continuous monitoring. Several studies have explored the use of optical (Dechka et al 2002) and SAR data (Kushwaha et al 2000; Henderson and Lewis, 2008) in wetland classification. A knowledge based hierarchical decision tree method was used for a pilot study of automated wetland feature extraction during the pre and post monsoon period (Subramaniam and Saxena 2011). A key requirement in all the models is the spatial extent of the wetlands which is tedious and cumbersome if done through traditional methods of inventorying and mapping. With the advent of big data and open source APIs like Google Earth Engine (GEE), regular monitoring of wetland spatial dynamics is possible. Google Earth Engine provides cloud platform for big data processing through freely available satellite data including those of Landsat-8, Sentinel-1 and Sentinel-2 (Shelestov et al, 2017). Synergic application of classification methods of GEE and time series analysis can aid in discerning the surface water dynamics of wetlands.

We present a novel approach using the computational power of GEE and time series data to assess the spatiotemporal dynamics of large Indian Wetlands. In this article

\footnotetext{
${ }^{*}$ Corresponding author
} 
we employ a knowledge based Decision tree method based on Normalised difference vegetation and modified normalized different water indices to capture the large wetland classes (area $>6000$ hectares) over a period of five years from April 2013 to June 2018. We also posit key temporal hydrological variables like the mean water extent, peak water day, storage cycle to properly classify the temporal dynamics of the wetlands. This would prove useful in understanding the time series behaviour in the form of rising and drying cycles of the water bodies. Furthermore, we analyse the behaviour of each water body in terms of their maximum and minimum extents, coefficient of variation of the spatial extent for better characterisation of temporal cycle.

\section{MATERIALS AND METHODS}

\subsection{Study Area}

In this study we focus on the large wetlands of India. NWIA estimated that wetlands cover around $4.63 \%$ of geophysical area of the country. Nearly 2 lakh wetland bodies were mapped during National Wetland Inventory Assessment carried out using IRS-P6 LISS-3 images at 1:50,000 scale for the year 2006-07 (Panigrahy et al, 2012). In this study large water bodies with spatial extent greater than 6000 ha were used. These water bodies cover different wetland classes like reservoirs, tanks, lakes and lagoons. Around 75 water bodies were identified and shown in figure 1 .

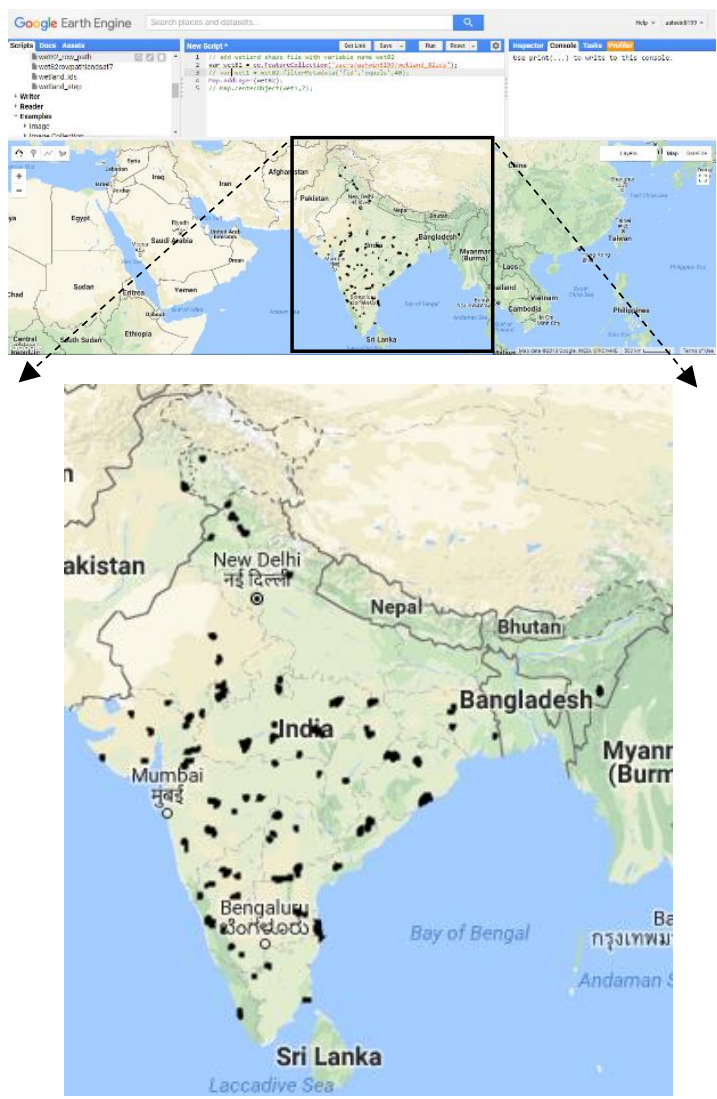

Figure 1: Large wetlands of India shown in the Google earth engine. GEE platform comprises of scripts, console and map as shown in top figure. The zoomed region in the bottom figure shows the spatial distribution of large wetlands in India.

\subsection{Data Used}

Landsat 8 OLI atmospheric corrected surface reflectance data have been in this study. GEE assigns a unique nomenclature to each data in it's archive. The Landsat 8 atmospheric corrected surface reflectance images (LANDSAT $\backslash L C 08 \backslash C 01 \backslash T 1 S R$ ) have been used from the GEE archive. The images contain five visible - Near Infrared bands and two Short wave infrared bands, acquired at 30-meter spatial resolution with 16 days' repeativity, acquired during the period April 2013 to June 2018. The images with cloud cover more than 20 percent have not been used in the study. A total of 1071 Landsat8 images have been used for understanding surface water dynamics of 75 wetlands spread all over India.

\subsection{Google Earth Engine platform}

The extensive amount of data obtained through plethora of remote sensing platforms with high spatial and temporal resolutions elucidate the use of high end computational resources. Google Earth Engine(GEE) being an open Application Programing Interface (API), offers free computational resources and satellite data on cloud computational platform, thus minimising the users requirement for computational resources and data availability (GEE 2017). GEE provides easy access to large archives of remote sensing data with computational power to through JavaScript minimizes the complexity of the computing facility. There has been a surge in literature employing the prowess of GEE for different applications like land use land cover mapping (Jacobson et al 2015, Huang et al 2017), vegetation mapping (Xiong et al, 2017, Shelestov et al 2017, Dong et al 2016), land surface temperature (Horowitz 2015), urban mapping (Patel et al 2015) etc.

\subsection{Water body delineation}

Several supervised and unsupervised classification techniques have been used for wetland mapping, prominent among them being Maximum likelihood (Arzandeh and Wang 2002, Brisco et al 2011, Gosselin et al 2014), Decision Tree (Powers et al 2012, Reschke et al 2012, Gosselin et al 2014), Support vector machine and KNN (Fix and Hodges Jr. 1951, Qian et al 2014). A knowledge based Decision Tree (DT) model has been employed to cluster the classes according to Normalized Difference Vegetation Index (NDVI) and Modified Normalized Difference Water Index (MNDWI) distribution. The decision rule to delineate water and nonwater classes is defined by-

If NDVI $<0$ and MNDWI $>=0$ : Water Class

Else if NDVI > $=0$ and MNDWI $<0$ : Non-Water class

\subsection{Modified Gaussian Model Fit}


Modified Gaussian model was first used by Sunshine et al in 1990 for deconvolution of the mineral absorption band from continuous removed spectra. The model is sum of number of Gaussian model based on the number of observation event in the series. Mathematically it is defined as

$S(t)=\sum_{i=1}^{n} a_{i} \times \exp \left(\frac{t-t_{o i}}{t_{s i}}\right)$

Where $S(t)$ is Surface water extent of water body at time

$\mathrm{n}$ is the number of Gaussian;

$a_{i}$ is amplitude of the Gaussian;

$t_{\text {oi }}$ is mean of each gaussian and

$t_{\mathrm{si}}$ is variance of individual gaussian.

This Model have been used to derive various surface water dynamics of wetlands of India.

\section{RESULTS AND DISCUSSION}

\subsection{Surface water extent}

For analysis of seasonal surface water dynamics, decision tree classifier exhibited a sufficiently high accuracy in delineation of water and non-water classes. Inaccuracies in the Decision tree classifier generally arise due to the effect of algal bloom, shallow water pixels and high turbid regions. Since large wetlands have been used in this study, such inaccuracies are not so prominent. The effect of such inaccuracies need to be taken into account while considering smaller wetlands. Classification accuracy is calculated over the selected wetland and compared with two component bimodal Gaussian mixture model. Overall accuracy of Decision tree was found to be $98.37 \%$ and kappa coefficient as 0.9475 . The surface extent of water body range from 4479 ha (Pench Reservoir in Maharashtra) to 101177 ha (Chilika Lagoon in Orissa).

Figure 2 illustrates the annual variation of Surface water extent with respect to mean storage area from year 2013 to 2018 for 75 major wetlands of India. The five-year time series is generated using single order sigmoidal function and the mean variations are shown. For the study period, it was observed maximum number of wetlands had a shrunk storage area (Figure 2f). $82.66 \%$ of wetlands show shrinkage in spatial extent in the year 2015-2016 followed by 2017-2018 which accounts for $62.66 \%$ of wetlands below mean storage area. 2013-2014 can be considered as by far the best year in terms of surface extent accounting for maximum of $84 \%$ of wetlands above mean area.

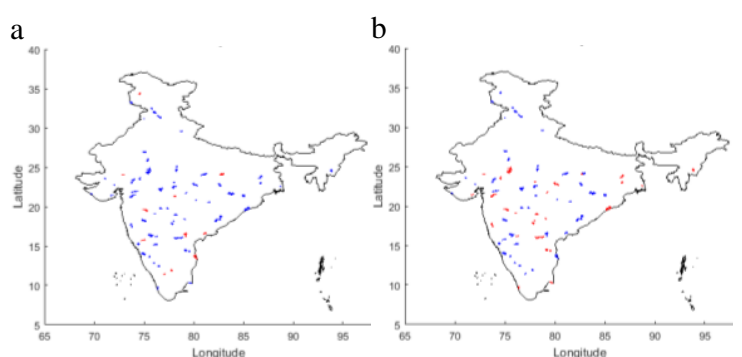

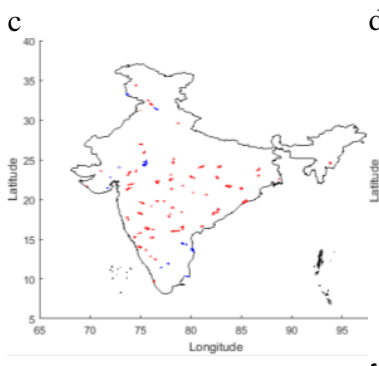
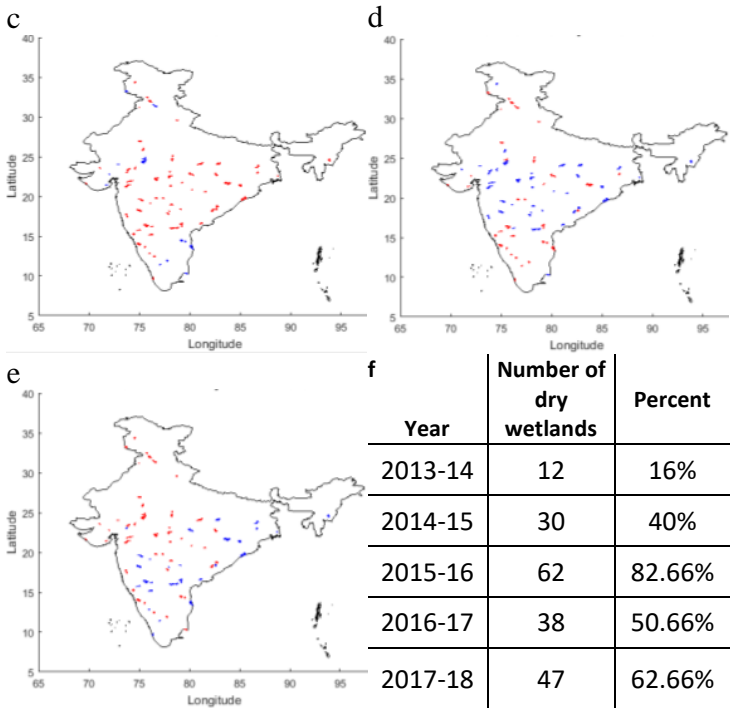

Figure 2: (a-e) represent annual deviation from 5 year mean storage area for the 75 wetlands. Wetlands with positive deviation are shown in blue whereas those with negative deviation (dry wetlands) are shown by Red colour. (f) summarises the number of wetlands that have shown negative deviation as a percentage of total wetlands.

\subsection{Surface water dynamics}

The time series of surface water extent is dominated by seasonal patterns. The analysis has been performed for all the wetlands but we present results for Dharoi reservoir derived from GEE's console which can be exported as a worksheet. The time series plot of surface extent of Dharoi reservoir is shown in Figure 3. The Surface extent is dominated by annual variation of precipitation and its seasonal behaviour. The maximum storage area occurs in November and descends till July. The images from midJune to October is generally cloudy hence we see missing data points in this period.

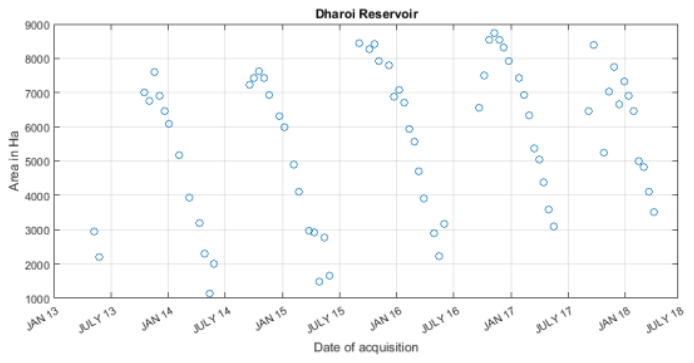

Figure 3: Time series plot of surface water extent derived over Dharoi reservoir, Gujarat from GEE.

The Modified Gaussian model fitting coefficients designate to various hydrological parameters of the water body as shown in figure 4 . The amplitude of each Gaussian mode $\left(a_{i}\right)$ denotes maximum surface water extent for each year (i). The mean of each mode $\left(t_{0 i}\right)$ denotes peak water day corresponding to $a_{i}$,variance $\left(\mathrm{t}_{\mathrm{si}}\right)$ represents the annual water storage cycle. The modified 
Gaussian model has been found to be a good fit with highest $\mathrm{R}^{2}=0.84$ amongst the 75 wetlands, with overall mean $\mathrm{R}$ value for all wetlands being 0.65 .

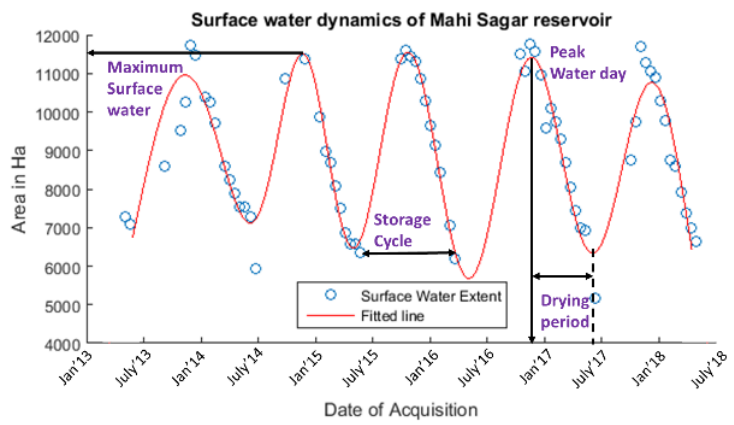

Figure 4: Time series plot of surface water extent and Modified Gaussian model fit derived over Mahi Sagar reservoir, Gujarat from GEE.

Analysis of various parameters for different wetlands, we have found that Chilika lagoon has longest storage cycle of 239 days because it is blackish water body whereas Tungabhadra reservoir has shortest storage cycle of just 96 days. On an average the storage cycle of these large wetlands is around 177 days. The spatial spread of storage cycle days is shown in figure $5 \mathrm{a}$. The storage cycle is an indicator of the water retention capacity of the wetland and assumes importance as a source of water for irrigation.

Similarly, maximum peak day has also been analysed. It has been found that Mangla dam attains its maximum surface extent in the first week of October, whereas Harike wetland peaks in April. The spatial distribution of peak days is classified month wise and is shown in figure $5 \mathrm{~b}$. Maximum peak day shows its strong correlation with climatological rainfall in its catchment area. An early peak indicates rainfall as major source of water. We opine that the delay in peak days may be due to release of water from upstream controlled reservoirs.

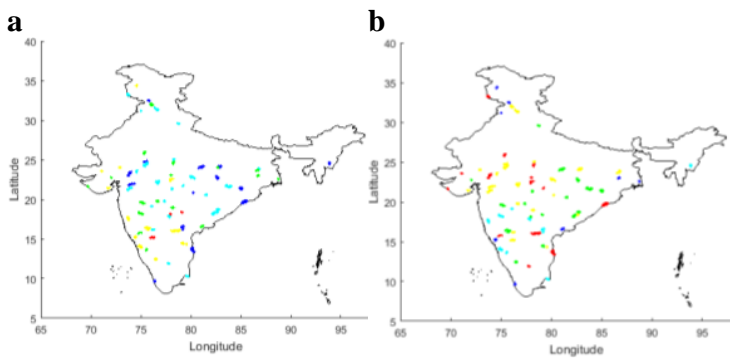

Figure 5: Temporal parameters like storage cycle, maximum peak day are shown for the wetlands. (a) Storage cycle $\left(t_{s}\right)$ of 75 wetlands. Wetlands with $t_{s}<125$ days (Red), $125<\mathrm{t}_{\mathrm{s}}<150$ days (Yellow), $150<\mathrm{t}_{\mathrm{s}}<175$ days (Green), $175<\mathrm{t}_{\mathrm{s}}<200$ days (Cyan), $200<\mathrm{t}_{\mathrm{s}}$ days (Blue). (b) This figure shows the period during which the wetlands attain maximum peak storage $\left(\mathrm{t}_{0}\right)$. Wetlands that peak before November are shown in Red, in November as Yellow, December in Green, during January in Cyan and post January peaking wetlands with Blue.
From the two images shown in figure 6 it is clear that a majority of wetlands had minimum surface extent in the year 2015-16 whereas 2013-14 witnessed majority of wetlands having maximum surface extent. We observed an overall decreasing trend in the surface extent of large wetlands of India.
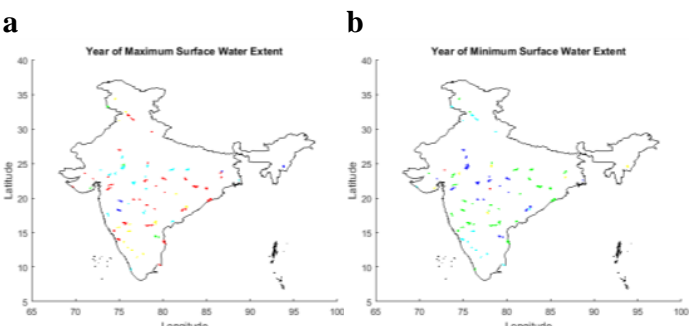

Figure 6: Years of maximum (a) and minimum (b) surface water extent of each wetland. Denotations are Red: 2013-14; Yellow: 2014-15; Green: 2015-16; Cyan: 2016-17 and Blue: 2017-18

To understand the retention capacity and effect of climatological parameter on these wetlands the coefficient of variation $(\mathrm{CV})$ of the extent was calculated. In the Figure 7 , the spatial variability of the $\mathrm{CV}$ of wetlands is shown.

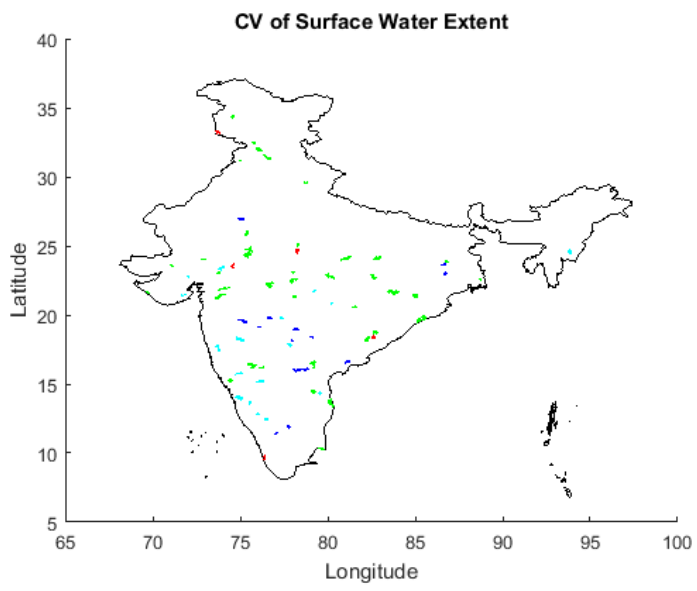

Figure 7: Illustration of Coefficient of Variation(CV). $\mathrm{CV}<\mu-\sigma$ in Red, $\mu-\sigma<\mathrm{CV}<\mu$ in Green, $\mu<\mathrm{CV}<\mu+\sigma$ in Cyan and $\mathrm{CV}>\mu+\sigma$ in blue.

\subsection{Direction of Future Research}

Several challenges arise in mapping surface water extents and their dynamics from remote sensing data. The presence of algae, highly turbid and shallow water lead to incorrect classification of water as land. Mountain and cloud shadows often get misclassified as water. Hence an improved wetland classification is required to improve the surface extent accuracy.

Missing data due to cloud cover limits our data points to study only drying pattern of the wetland. Incorporating SAR data to the study will help complete the time series irrespective of cloud cover. There is a need to investigate relation of water extent with various climatological 
parameters like rainfall, evaporation, wind speed, humidity and surface temperature etc. A long term time series analysis by including previous Landsat series data in analysis will better help to estimate the mean storage area of wetlands. This study focused on major wetland bodies with average surface extent greater than 6000 ha. Several studies have pointed to a better spatial analysis of smaller wetlands which are critical for various ecological function. Future studies may need to increase the study to larger number of wetland bodies including small water bodies for better understanding of national scale surface water dynamics

\section{CONCLUSION}

In this paper we have demonstrated the computational power of GEE in application to surface hydrology. Simple decision tree model of land and water have sufficiently high classification accuracy for large water bodies because of distinct separable indices for deep waters. We Found gaussian mixture model to be a strong tool to identify various parameters in time series plot assume physical meaning, useful for understanding the temporal dynamics. The number of modes of the Gaussian is based on the number of events in the series. The peak position of surface extent and water cycle period of the reservoir can help in better management policies to control the water discharge from the reservoirs. An improved model can be implemented in future to also study the decay pattern of the surface water extent.

\section{ACKNOWLEDGEMENT}

The authors express their sincere gratitude to Shri D K Das, Director, SAC, for his encouragement. The authors are thankful to Dr. Raj Kumar, Deputy Director, EPSA, SAC, Dr. A. S. Rajawat Group Director. GHCAG and Dr. R. P. Singh, Head, LHD for providing overall guidance and keen interest. The authors are also thankful to Google Earth Engine for providing the data source and its computational facilities.

\section{REFERENCES}

Arzandeh, Sepideh, and Jinfei Wang. "Texture evaluation of RADARSAT imagery for wetland mapping." Canadian Journal of Remote Sensing 28, no. 5 (2002): 653-666.

Brisco, B., M. Kapfer, T. Hirose, B. Tedford, and J. Liu. "Evaluation of C-band polarization diversity and polarimetry for wetland mapping." Canadian Journal of Remote Sensing37, no. 1 (2011): 82-92.

Dechka, J. A., et al. "Classification of wetland habitat and vegetation communities using multi-temporal Ikonos imagery in southern Saskatchewan." Canadian Journal of Remote Sensing 28.5 (2002): 679-685.

Dong, Jinwei, et al. "Mapping paddy rice planting area in northeastern Asia with Landsat 8 images, phenologybased algorithm and Google Earth Engine." Remote sensing of environment 185 (2016): 142-154.
Ferone, J. M., and K. J. Devito. "Shallow groundwatersurface water interactions in pond-peatland complexes along a Boreal Plains topographic gradient." Journal of Hydrology 292, no. 1-4 (2004): 75-95.

Fix, Evelyn, and Joseph L. Hodges Jr. Discriminatory analysis-nonparametric discrimination: consistency properties. California Univ Berkeley, 1951.

Gallant, Alisa L. "The challenges of remote monitoring of wetlands." (2015): 10938-10950.

GEE (2017). Google Earth Engine, last updated May 25th, 2017. URL: https://developers.google.com/earthengine/\#about-google-earth-engine.

Gosselin, Gabriel, Ridha Touzi, and François Cavayas. "Polarimetric Radarsat-2 wetland classification using the Touzi decomposition: case of the Lac Saint-Pierre Ramsar wetland." Canadian Journal of Remote Sensing 39.6 (2014): 491-506.

Hammer, D. E., and R. H. Kadlec. "A model for wetland surface water dynamics." Water Resources Research 22.13 (1986): 1951-1958.

Henderson, Floyd M., and Anthony J. Lewis. "Radar detection of wetland ecosystems: a review." International Journal of Remote Sensing 29, no. 20 (2008): 5809-5835.

Horowitz, Franklin G. "MODIS Daily Land Surface Temperature Estimates in Google Earth Engine as an Aid in Geothermal Energy Siting." Proceedings World Geothermal Congress. 2015.

Huang, Huabing, et al. "Mapping major land cover dynamics in Beijing using all Landsat images in Google Earth Engine." Remote Sensing of Environment 202 (2017): 166-176.

Jacobson, Andrew, et al. "A novel approach to mapping land conversion using Google Earth with an application to East Africa." Environmental Modelling \& Software 72 (2015): 1-9.

Junk, Wolfgang J. "Flood pulsing and the linkages between terrestrial, aquatic, and wetland systems." Internationale Vereinigung für theoretische und angewandte Limnologie: Verhandlungen 29, no. 1 (2005): 11-38.

Kushwaha, S. P. S., R. S. Dwivedi, and B. R. M. Rao. "Evaluation of various digital image processing techniques for detection of coastal wetlands using ERS-1 SAR data."International Journal of Remote Sensing 21, no. 3 (2000): 565-579.

Liang, Xu, et al. "A simple hydrologically based model of land surface water and energy fluxes for general circulation models." Journal of Geophysical Research: Atmospheres $99 . \mathrm{D} 7$ (1994): 14415-14428.

Panigrahy, Sushma, T. V. R. Murthy, J. G. Patel, and T. S. Singh. "Wetlands of India: inventory and assessment at 1 : 
50,000 scale using geospatial techniques." Current science(2012): 852-856

Papa, Fabrice, et al. "Variations of surface water extent and water storage in large river basins: A comparison of different global data sources." Geophysical Research Letters 35.11 (2008).

Patel, Nirav N., et al. "Multitemporal settlement and population mapping from Landsat using Google Earth Engine." International Journal of Applied Earth Observation and Geoinformation 35 (2015): 199-208.

Powers, Ryan P., Geoffrey J. Hay, and Gang Chen. "How wetland type and area differ through scale: A GEOBIA case study in Alberta's Boreal Plains." Remote Sensing of Environment 117 (2012): 135-145.

Qian, Yuguo, et al. "Comparing machine learning classifiers for object-based land cover classification using very high resolution imagery." Remote Sensing 7.1 (2014): 153-168.

Reschke, Julia, Annett Bartsch, Stefan Schlaffer, and Dmitry Schepaschenko. "Capability of C-band SAR for operational wetland monitoring at high latitudes." Remote Sensing 4, no. 10 (2012): 2923-2943.
Seitzinger, Sybil P. "Linkages between organic matter mineralization and denitrification in eight riparian wetlands." Biogeochemistry 25, no. 1 (1994): 19-39.

Shelestov, Andrii, et al. "Exploring Google earth engine platform for Big Data Processing: Classification of multitemporal satellite imagery for crop mapping." Frontiers in Earth Science 5 (2017): 17

Subramaniam, S., and Manoj Saxena. "Automated Algorithm for Extraction of Wetlands from IRS Resourcesat Liss III Data." ISPRS-International Archives of the Photogrammetry, Remote Sensing and Spatial Information Sciences 3820 (2011): 193-198.

Sunshine, Jessica M., Carle M. Pieters, and Stephen F. Pratt. "Deconvolution of mineral absorption bands: An improved approach." Journal of Geophysical Research: Solid Earth95.B5 (1990): 6955-6966.

Winter, Thomas C. "Ground water and surface water: the linkage tightens, but challenges remain." Hydrological Processes 15, no. 18 (2001): 3605-3606.

Xiong, Jun, et al. "Automated cropland mapping of continental Africa using Google Earth Engine cloud computing." ISPRS Journal of Photogrammetry and Remote Sensing 126 (2017): 225-244. 